\title{
Report of Open Cholecystectomy in Two Obese Patients with Severe Lung Disease under Awake Thoracic Epidural Anaesthesia
}

Dalamagka $\mathbf{M}^{*}$ and Kontovitsis $\mathbf{C H}$

Department of Anaesthesiology, General Hospital of Edessa, Greece

\begin{abstract}
We report 2 cases of cholecystitis and cholelithiasis in patients with obesity, chronic obstructive pulmonary disease, American Society of Anaesthesiologists classification IV, that they were treated with open cholecystectomy. In both cases, successful open cholecystectomy was performed, under thoracic epidural anaesthesia, and the patients recovered uneventfully.
\end{abstract}

Keywords: Cholecystectomy; Chronic obstructive pulmonary disease

\section{Introduction}

Thoracic epidural anaesthesia is commonly used for everyday procedures. After major abdominal surgery, thoracic epidural anaesthesia results in pain free ventilation and increases the abdominal ventilation, resulting in a lower incidence of postoperative complications $[1,2]$. There is a lack of data in the literature regarding open cholecystectomy being performed under epidural anaesthesia alone, especially in patients who are deemed at high risk for general anesthesia. In this case report, we describe two cases of awake open cholecystectomy in two high-risk surgical patients performed under thoracic epidural anaesthesia.

\section{Case Report}

The patients were 78-years-old and 80 years-old, American Society of Anaesthesiologists classification IV, both male, weighed 105 and $120 \mathrm{Kg}$ respectively. They were admitted to the emergency room with intermittent sharp and dull pain to their right lower quadrant. Their medical history included obesity, decrease cardiac output, chronic obstructive pulmonary disease, dyspneic on minimal exertion, hypertensive and a room oxygen saturation of $87-90 \%$ which improved with supplemental oxygen. Axial CT image showed in both cases multiple low-attenuation areas of emphysema. The percentage of predicted FEV1 was $45.6 \%$ and $40.8 \%$ respectively.

The patients were premedicated with $1 \mathrm{mg}$ of midazolam intravenously before the procedure. Continuous pulse oximetry, blood pressure cuff and electrocardiographic monitoring were performed. The patients were placed in seated position. A nasogastric tube was inserted. For epidural anaesthesia, a midline approach was used under complete aseptic preparation. Local anaesthesia (2\% lidocaine $2 \mathrm{ml}$ was injected into the skin. An 18-gauge Tuohy needle was introduced at T11/T12 intervertebral space. The epidural space was identified using the loss of resistance technique and an epidural catheter was passed through the needle. The Aspiration test for subarachnoid and intravascular placement was negative. A test dose of $2 \%$ lidocaine $2 \mathrm{ml}$ was administrated through the epidural catheter with no change on sensorimotor examination. Epidural anaesthesia was established with $12 \mathrm{ml}$ bupivacaine $0.5 \%$ and $0.05 \mathrm{mg}$ Fentanyl. The patients remained hemodynamically stable during the surgery. The surgery was completed in approximately 2 hours. Half an hour before the end of surgery was given $2 \mathrm{mg}$ epidural morphine for postoperative coverage requirements. Postoperative analgesia was satisfactory and the patients remained calm in the postoperative period.

\section{Discussion}

The steep head-down position in an anesthetized patient results in atelectasis and sometimes hypoxemia due to decreased functional residual capacity. With induction of anesthesia, the increased central blood volume, cephalad displacement of the diaphragm, and the weight of the abdominal contents impending diaphragmatic excursion reduces pulmonary vital capacity. As a result of these changes, impedance of the chest wall and lung increases, an effect which is more pronounced in elderly and obese patients [3]. Respiratory failure in morbidly obese patients is associated with greater in-hospital mortality after bariatric surgery [4]. Patients under regional anesthesia usually develop fewer pulmonary complications than those under general anesthesia [5]. Regional block such as low thoracic epidural, spinal, and combined spinal-epidural blocks have been used in patients with relevant medical problems [6-8]. There are several advantages to using regional anesthesia for bariatric surgery in both cases. First, preoperative pulmonary function parameters may be maintained throughout the surgery [9-11]. In contrast, pulmonary function parameters may not return to preoperative levels until the seventh postoperative day in patients receiving general anesthesia [12]. Thoracic epidural anaesthesia and analgesia can decrease the incidence of postoperative morbidity and mortality. Thoracic epidural anaesthesia improves postoperative analgesia, resulting in increased patient satisfaction [13,14]. However, awake thoracic epidural anaesthesia as the sole anaesthetic technique was successfully employed for risk surgical patients with chronic obstructive pulmonary disease undergoing abdominal surgery, regarding postoperative pulmonary infections, better pain relief and faster return of bowel activity.

\section{References}

1. Kopacz DJ, Pollack JE (1998) Thoracic epidural anesthesia for chest and upper abdominal surgery. J Crit Care 17: 38-48.

*Corresponding author: Maria Dalamagka, Consultant Anaesthetist, Department of Anaesthesiology, General Hospital of Edessa, Eddessa, Pella-58200, Greece, Tel: 00302381501721; E-mail: mary.dalamaga@gmail.com

Received October 27, 2015; Accepted November 04, 2015; Published November 09, 2015

Citation: Dalamagka M, Kontovitsis $\mathrm{CH}(2015)$ Report of Open Cholecystectomy in Two Obese Patients with Severe Lung Disease under Awake Thoracic Epidural Anaesthesia. Pain Manage Med 1: 104

Copyright: (c) 2015 Dalamagka M, et al. This is an open-access article distributed under the terms of the Creative Commons Attribution License, which permits unrestricted use, distribution, and reproduction in any medium, provided the original author and source are credited. 
Citation: Dalamagka M, Kontovitsis CH(2015) Report of Open Cholecystectomy in Two Obese Patients with Severe Lung Disease under Awake Thoracic Epidural Anaesthesia. Pain Manage Med 1: 104

2. Waurick $\mathrm{R}$, Van Aken $\mathrm{H}$ (2005) Update in thoracic epidural anaesthesia. Best Pract Res Clin Anaesthesiol 19: 201-213.

3. Kalmar AF, Foubert L, Hendrickx JF, Mottrie A, Absalom A, et al. (2010) Influence of steep Trendelenburg position and $\mathrm{CO}(2)$ pneumoperitoneum on cardiovascular, cerebrovascular, and respiratory homeostasis during robotic prostatectomy. Br J Anaesth 104: 433-439.

4. Masoomi H, Reavis KM, Smith BR, Kim H, Stamos MJ, et al. (2013) Risk factors for acute respiratory failure in bariatric surgery: data from the Nationwide Inpatient Sample, 2006-2008. Surg Obes Relat Dis 9: 277-281.

5. Pedersen T, Viby-Mogensen J, Ringsted C (1992) Anaesthetic practice and postoperative pulmonary complications. Acta Anaesthesiol Scand 36: 812-818.

6. Gramatica L Jr, Brasesco OE, Mercado Luna A, Martinessi V, Panebianco G, et al. (2002) Laparoscopic cholecystectomy performed under regional anesthesia in patients with chronic obstructive pulmonary disease. Surg Endosc 16: 472-475.

7. Hamad MA, El-Khattary OA (2003) Laparoscopic cholecystectomy under spinal anesthesia with nitrous oxide pneumoperitoneum: a feasibility study. Surg Endosc 17: 1426-1428.

8. van Zundert AA, Stultiens G, Jakimowicz JJ, van den Borne BE, van der Ham
WG, et al. (2006) Segmental spinal anaesthesia for cholecystectomy in a patient with severe lung disease. $\mathrm{Br} \mathrm{J}$ Anaesth 96: 464-466.

9. Kim YI, Lee JS, Jin HC, Chae WS, Kim SH (2007) Thoracic epidural anesthesia for laparoscopic cholecystectomy in an elderly patient with severely impaired pulmonary function tests. Acta Anaesthesiol Scand 51: 1394-1396.

10. van Zundert AA, Stultiens G, Jakimowicz JJ, van den Borne BE, van der Ham WG, et al. (2006) Segmental spinal anaesthesia for cholecystectomy in a patient with severe lung disease. $\mathrm{Br} \mathrm{J}$ Anaesth 96: 464-466.

11. Pursnani KG, Bazza Y, Calleja M, Mughal MM (1998) Laparoscopic cholecystectomy under epidural anesthesia in patients with chronic respiratory disease. Surg Endosc 12: 1082-1084.

12. Nguyen NT, Anderson JT, Budd M, Fleming NW, Ho HS, et al. (2004) Effects of pneumoperitoneum on intraoperative pulmonary mechanics and gas exchange during laparoscopic gastric bypass. Surg Endosc 18: 64-71.

13. Hurley RW, Wu C (2009) Acute Postoperative Pain. In Miller's Anesthesia, (7Thedn) Churchill Livingstone, Philadelphia.

14. van Lier F, van der Geest PJ, Hoeks SE, van Gestel YR, Hol JW, et al. (2011) Epidural analgesia is associated with improved health outcomes of surgical patients with chronic obstructive pulmonary disease. Anesthesiology 115: 315-321. 